\title{
An overload hypothesis for pulmonary clearance of UICC amosite fibres inhaled by rats
}

\author{
R E BOLTON, J H VINCENT, A D JONES, J ADDISON, AND S T BECKETT \\ From the Institute of Occupational Medicine, Edinburgh, UK
}

ABSTRACT Two types of experiments were carried out to examine the effects of deposition and clearance on the accumulation in the lungs of rats of inhaled fibres of UICC amosite. In the first experiment the mass lung burdens of the dust in question were measured as a function of the time at which animals were killed after the cessation of the six week exposure period, and in the second the masses were measured for rats removed from exposure and killed at intervals during the exposure period itself. The experimental conditions were chosen to complement those of earlier work. Taken together with the results of that earlier work, the new results provide the basis for a simple mathematical model of the kinetics of deposition and clearance which appears to account for the major observed trends. Most significantly, there is strong evidence for an overload of clearance at high lung burdens (exceeding about $1500 \mu \mathrm{g} / \mathrm{rat}$ ), in which a breakdown occurs of the intermediate rate clearance mechanisms (time constants of the order of 12 days). This hypothesis is supported for inhaled asbestos dust, quartz dust, and diesel fume by results obtained elsewhere. Biological explanations for the clearance overload hypothesis are at present speculative, involving discussion of the role of the macrophage in pulmonary clearance. It is believed that the clearance overload hypothesis could have possible consequences for people occupationally exposed to airborne dusts.

\begin{abstract}
Animal inhalation studies are useful for examining the potential consequences in man of asbestos exposure under defined conditions. Several investigations into the pathological effects of the long term exposure of rats to asbestos minerals have been reported as part of a continuing programme. ${ }^{1-3}$ Complementary studies to examine the kinetics of the deposition and clearance of inhaled asbestos fibres are also being carried out, and the present paper follows on from earlier work reported by Middleton et al $^{45}$

Several studies into the pulmonary deposition and clearance of inhaled asbestos fibres have been reported. The earliest was by Wagner and Skidmore, who examined the clearance of chrysotile, crocidolite, and amosite in separate groups of rats exposed in inhalation chambers, and reported approximately exponential clearance over a two month period of observation. ${ }^{6}$ The results for chrysotile differed from those for the amphiboles, having apparently both a smaller deposition fraction
\end{abstract}

Received 22 July 1982

Accepted 26 August 1982 and a faster clearance rate. Using "nose-only" inhalation techniques and brief exposures (up to 30 minutes), Morgan et al failed to confirm either the lower initial retention or the faster clearance of chrysotile. ${ }^{78}$ Using exposure chamber facilities similar to those of Wagner and Skidmore, ${ }^{6}$ Middleton et al confirmed the relatively lower retention of reported chrysotile but showed similar overall clearance rates for all three dusts examined (UICC chrvsotile, crocidolite, and amosite) ${ }^{45}$

One interesting finding of the deposition and clearance studies described by Middleton $e a{ }^{45}$ was that the clearance rates calculated from the data for the short term (six weeks) exposures seem substantially to underestimate the magnitudes of the lung burden found when similar groups of rats were exposed to the same dusts for one year as part of a chronic toxicity study. ${ }^{1}$ It was suggested that the observed higher than expected lung burdens could result from the sequestration of a greater proportion of inhaled dust in a supposed slower clearing pulmonary "compartment."s In the present work we have set out to investigate further the deposition and clearance of inhaled asbestos fibres, in particular to examine the competition that exists between those 
processes during continuous exposure and whether clearance itself is affected by the actual magnitude of the lung burden (especially at high burdens).

\section{Methods}

Five experiments were carried out, using groups of 48 outbred male SPF Wistar rats of the AF/HAN strain. The inhalation and dusting facilities and procedures were similar to those described elsewhere. ${ }^{459}$ Clouds of UICC amosite (chosen because it is relatively easy to evaluate and chemically more stable than, say, chrysotile) were generated in a $1 \mathrm{~m}^{3}$ experimental chamber, and the rats in each separate experiment were exposed for up to 210 hours, comprising seven hours a day, five days a week, over six weeks. Dust exposure levels were defined for each experiment in terms of the average mass concentrations of so-called "respirable" dust as measured using a Casella type 113A gravimetric sampler. ${ }^{10}$ In the first two experiments, carried out at high target dust concentrations of 30 and $90 \mathrm{mg} \mathrm{m}^{-3}$ respectively (corresponding to number concentrations of about 1500 and 4500 optically visible fibres $\mathrm{ml}^{-1}$ respectively, and referred to here as amosite 30 and amosite 90), exposure took place under normal daylight conditions, when the animals were at their least active. In the next two experiments, carried out at lower target concentrations of 5 and $10 \mathrm{mg} \mathrm{m}^{-3}$ (corresponding to about 250 and 500 optically visible fibres $\mathrm{ml}^{-1}$ respectively), exposure took place under reverse daylight conditions, when the chamber was blacked out by day while dusting was taking place and artificially illuminated at night. We refer to these experiments as reverse daylight amosite 5 and reverse daylight amosite 10 . The conditions for all these four experiments were chosen so as to complement those of the earlier experiments reported by Middleton et al..$^{45}$

In these four experiments the rats were exposed for the full six week inhalation period. At the end of that time they were killed in subgroups of eight animals at roughly monthly intervals, the first at three or four days after the cessation of exposure to allow near completion of the fast phase of ciliary clearance from the trachea and the bronchi. The lungs were excised from the animals at necropsy, and most were used for subsequent quantitative asbestos mass burden analysis. Lungs from a few animals from each experiment were inflated with formol saline and processed for histological examination.

In the fifth experiment, carried out at a target respirable dust concentration of $10 \mathrm{mg} \mathrm{m}^{-3}$, the inhalation history was modified in that rats were removed from the chamber in subgroups of eight at regular weekly intervals during the inhalation period. For each subgroup, four animals were killed at three days after removal from the chamber and the other four at 38 days. We refer to this experiment as "build-up" amosite 10.

The lung burden recovery and mass estimation procedures have evolved from those used by Middleton et al. ${ }^{45}$ The excised rat lungs were weighed, dried for 36 hours at $120^{\circ} \mathrm{C}$, reweighed and incinerated in a low temperature radio frequency oxygen plasma $^{11}$ for about 100 hours (Nanotech, model No P100). The resulting ashes were weighed, immersed in $0.1 \mathrm{M} \mathrm{HCl}$ for 20 minutes, and briefly ultrasonicated. The insoluble residues were collected by filtration on $0.2 \mu \mathrm{m}$ pore size polycarbonate (Nuclepore) filters. These residues were then washed off the filters into platinum crucibles by further ultrasonication in alcohol, dried, and reweighed. About $250 \mathrm{mg}$ of potassium bromide $(\mathrm{KBr})$ was accurately weighed, added to the crucibles, and mixed with the residues by hand-grinding under alcohol, using an agate pestle and mortar, for about 15 minutes. The mixtures were finally dried at $120^{\circ} \mathrm{C}$ for several hours before pressing into $\mathrm{KBr}$ discs for infrared spectrophotometry. The infrared absorption spectra were recorded and the absorbances measured at a wavelength of $10 \mu \mathrm{m}$ (wave number $1000 \mathrm{~cm}^{-1}$ ). The masses of amosite in the discs were obtained by comparison of the measured absorbances with those of calibration discs prepared with respirable amosite collected from the exposure chamber using a Casella type 113A gravimetric dust sampler. In some preparations total extinction of the infrared spectrum occurred as a result of excessive mineral in the disc. In such cases a second disc was prepared by taking an aliquot of the first and adding $\mathrm{KBr}$ to make up the weight to about the required $250 \mathrm{mg}$.

\section{Results}

\section{CLEARANCE STUDIES}

For the amosite 30 and amosite 90 experiments, the average respirable dust concentrations over the actual periods of dusting were 28.4 and $91.9 \mathrm{mg} \mathrm{m}^{-3}$ respectively. Those for the reverse daylight amosite 10 and 5 experiments were 10.8 and $6.0 \mathrm{mg} \mathrm{m}^{-3}$ respectively. The lung burden data from these experiments are summarised in table 1 together with the earlier data of Middleton et al, ${ }^{45}$ for amosite 1, 5, and 10 respectively. From the table it appears, as expected, that the greater the level of dust exposure, the greater the lung burden, and the lung burden, for a given exposure level, falls with time of postexposure. Furthermore, the lung burdens for reverse daylight exposure are substantially 
greater than for the corresponding daylight exposure.

An appropriate way to portray these data graphically is to plot, as a function of time postexposure, the total measured lung burden per rat per unit average level of respirable dust exposure for normal breathing minute volume $(\mathrm{Z}$, expressed in units of $\mu \mathrm{g} / \mathrm{mg} \mathrm{m}^{-3}$ ). The latter requires for the reverse daylight experiments that the lung burdens should be adjusted to the same minute volume as for normaldaylight experiments-that is, based on the rat oxygen-uptake experiments of Middleton et al,45 they are scaled downwards by a factor of 1.25 . The full results are shown graphically in fig 1 . Assuming the most simplistic model, that deposition is directly proportional to the level of dust exposure and the rate of clearance is independent of the accumulated lung burden, then all the data should be described by a single unique relationship. This is clearly not the case. Despite the scatter on the data points, two main broad trends may be identified (as indicated by the eye-drawn broken lines on the graph). These are that $(a)$ for low cumulative lung burdens, clearance is initially rapid but then slows down, and $(b)$ for high cumulative lung burdens, clearance is apparently slower right from the first killing date. The transition between these two broad trends takes place for a lung burden in the range 800 to $1500 \mu \mathrm{g}$.

“BUILD-UP" STUDIES

For the "build-up" amosite 10 experiment, the final average respirable dust concentration at the end of six weeks was $9.9 \mathrm{mg} \mathrm{m}^{-3}$. The weekly averages were also close to that target. Table 2 summarises the data for the average lung burdens of the animals removed from the chamber at regular intervals during the exposure period (and killed in equal subgroups at three and 38 days respectively after removal). Lung burden per unit dust level $(Z)$ is shown as a function of time after the start of exposure in fig 2.

\section{PATHOLOGY}

Histological examination of sections taken from a representative selection of rat lungs showed no major structural changes. The only widespread and

Table 1 Data from asbestos clearance studies.

\begin{tabular}{|c|c|c|c|c|}
\hline \multirow{2}{*}{$\begin{array}{l}\text { Experiment (mean } \\
\text { respirable dust level) }\end{array}$} & \multirow{2}{*}{$\begin{array}{l}\text { Days after cessation } \\
\text { of exposure }\end{array}$} & \multicolumn{2}{|c|}{ Average total lung burden } & \multirow[t]{2}{*}{ Source } \\
\hline & & \multicolumn{2}{|c|}{$\stackrel{\mu g}{( \pm \text { standard error) }}$} & \\
\hline $\begin{array}{l}\text { Amosite } 30 \\
\left(28.4 \mathrm{mg} \mathrm{m}^{-3}\right)\end{array}$ & $\begin{array}{r}4 \\
35 \\
66 \\
105 \\
137\end{array}$ & $\begin{array}{l}2240 \pm \\
2191 \pm \\
2353 \pm \\
2149 \pm \\
1710 \pm\end{array}$ & $\begin{array}{l}178 \\
322 \\
334 \\
288 \\
272\end{array}$ & \\
\hline $\begin{array}{l}\text { Amosite } 90 \\
\left(91.9 \mathrm{mg} \mathrm{m}^{-3}\right)\end{array}$ & $\begin{array}{r}3 \\
41 \\
70 \\
125 \\
280\end{array}$ & $\begin{array}{r}10091 \pm \\
6449 \pm \\
7080 \pm \\
8599 \pm \\
4407 \pm\end{array}$ & $\begin{array}{r}1109 \\
749 \\
518 \\
1350 \\
340\end{array}$ & This work \\
\hline $\begin{array}{l}\text { Reverse daylight amosite } 5 \\
\left(6 \cdot 0 \mathrm{mg} \mathrm{m}^{-3}\right)\end{array}$ & $\begin{array}{r}3 \\
34 \\
70 \\
125 \\
278\end{array}$ & $\begin{array}{l}947 \pm \\
872 \pm \\
565 \pm \\
352 \pm \\
299 \pm\end{array}$ & $\begin{array}{r}39 \\
66 \\
37 \\
94 \\
98\end{array}$ & IIUS WOIK \\
\hline $\begin{array}{l}\text { Reverse daylight amosite } 10 \\
\quad\left(10.8 \mathrm{mg} \mathrm{m}^{-3}\right)\end{array}$ & $\begin{array}{r}4 \\
34 \\
71 \\
96 \\
124\end{array}$ & $\begin{array}{r}1873 \pm \\
1557 \pm \\
1243 \pm \\
966 \pm \\
1067 \pm\end{array}$ & $\begin{array}{r}77 \\
95 \\
120 \\
113 \\
52\end{array}$ & \\
\hline $\begin{array}{l}\text { Amosite } 1 \\
\quad\left(1.3 \mathrm{mg} \mathrm{m}^{-3}\right)\end{array}$ & $\begin{array}{r}5 \\
32 \\
66 \\
102 \\
128\end{array}$ & $\begin{array}{l}79 \pm \\
69 \pm \\
46 \pm \\
45 \pm \\
43 \pm\end{array}$ & $\begin{array}{r}6 \\
7 \\
18 \\
8 \\
21\end{array}$ & Middleton et als \\
\hline $\begin{array}{l}\text { Amosite } 5 \\
\left(4.6 \mathrm{mg} \mathrm{m}^{-3}\right)\end{array}$ & $\begin{array}{r}120 \\
5 \\
32 \\
66 \\
102 \\
128\end{array}$ & $\begin{array}{l}49 \pm \\
693 \pm \\
309 \pm \\
160 \pm \\
138 \pm \\
124 \pm\end{array}$ & $\begin{array}{l}21 \\
56 \\
39 \\
18 \\
18 \\
12\end{array}$ & Midaleton et al \\
\hline $\begin{array}{l}\text { Amosite } 10 \\
\left(9.3 \mathrm{mg} \mathrm{m}^{-3}\right)\end{array}$ & $\begin{array}{r}5 \\
32 \\
66 \\
102 \\
128\end{array}$ & $\begin{array}{r}1448 \pm \\
605 \pm \\
410 \pm \\
332 \pm \\
385 \pm\end{array}$ & $\begin{array}{r}169 \\
54 \\
48 \\
19 \\
43\end{array}$ & \\
\hline
\end{tabular}




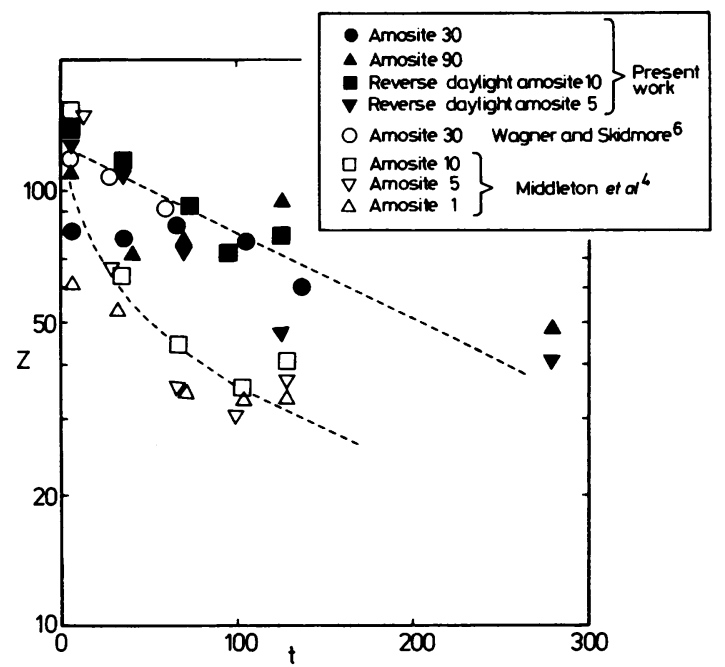

Fig 1 Lung burden per unit level of dust exposure $(Z$, in $\mu \mathrm{g} / \mathrm{mg} \mathrm{m}^{-3}$ ) as a function of time postexposure (t, in days).

consistent histopathological evidence of dust exposure was the presence of dust-laden macrophages in parenchymal lung of all animals.

\section{Discussion}

The present work provides evidence that the mechanisms of pulmonary clearance undergo a change when the lung burden exceeds a threshold in the range $800-1500 \mu \mathrm{g} / \mathrm{animal}$. The suggestion that such an observed slower overall rate of clearance is associated with an overload of "normal" pulmonary clearance finds support in other published studies relating to other types of dust. For example, the results of Klosterkotter and Buneman for the clearance of quartz dust inhaled by rats show a pronounced similarity to our results for amosite, ${ }^{2}$ although it was Ferin who pointed out that in their experiments the clearance rate of quartz started to decrease considerably for initial lung burdens exceeding $1000 \mu \mathrm{g} .{ }^{13}$ Le Bouffant also produced

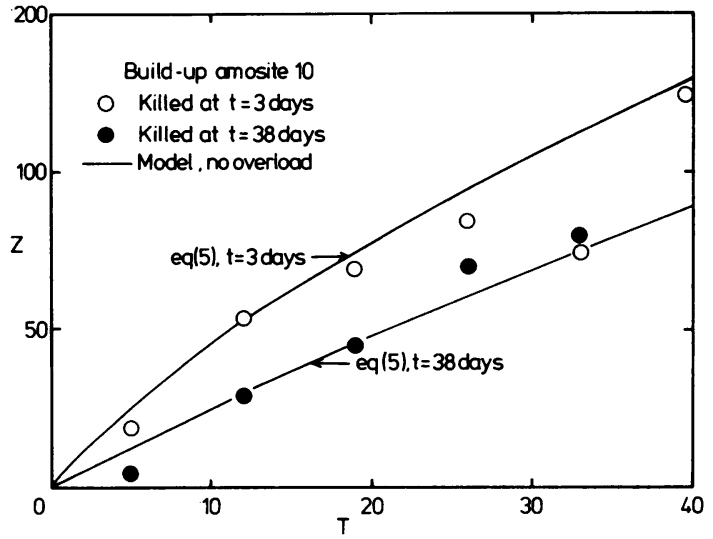

Fig 2 Lung burden per unit level of dust exposure ( $Z$, in $\left.\mu \mathrm{g} / \mathrm{mg} \mathrm{m}^{-3}\right)$ as a function of time after start of exposure ( $T$, in days).

clear evidence of an overload in rats exposed for more than five days to high concentrations of coal dust. ${ }^{14}$ More recently, a similar effect has been described by Vostal and his coworkers (at the EPA Diesel Emissions Symposium at Raleigh, NC, in October 1981) for the clearance of inhaled diesel particles. The results of Wagner and Skidmore ${ }^{6}$ for asbestos provide yet further evidence of clearance overload, and since their clearance data for amosite were obtained under exposure conditions similar to our own amosite 30 experiment, they may be inserted directly into the graph in fig 1 . When this is done, they are seen to exhibit similarly slow clearance. The faster overall rate of clearance that they report for chrysotile may be due not so much to any fundamental differences associated with asbestos type itself but rather to the fact that the lung burden at the end of exposure fell well short of the overload threshold. (The question of the relatively low deposition of chrysotile has been discussed by Middleton et al, ${ }^{4}$ who believed that it could be associated in some way with the peculiar "curly" nature of chrysotile fibres.)

Table 2 Data from asbestos build-up studies

\begin{tabular}{|c|c|c|c|}
\hline \multirow{3}{*}{$\begin{array}{l}\text { Experiment (mean } \\
\text { respirable dust level) }\end{array}$} & \multirow{3}{*}{$\begin{array}{l}\text { Days after start } \\
\text { of exposure }\end{array}$} & \multirow{2}{*}{\multicolumn{2}{|c|}{ Average total lung burden }} \\
\hline & & & \\
\hline & & \multicolumn{2}{|l|}{ Killed at 3 days } \\
\hline Build-up amosite $10\left(9.9 \mathrm{mg} \mathrm{m}^{-3}\right)$ & $\begin{array}{r}5 \\
12 \\
19 \\
26 \\
33 \\
40\end{array}$ & $\begin{aligned} 203 & \pm 66 \\
548 & \pm 14 \\
678 & \pm 81 \\
838 & \pm 124 \\
757 & \pm 118 \\
1225 & \pm 80\end{aligned}$ & $\begin{array}{r}35 \pm 17 \\
291 \pm 49 \\
439 \pm 55 \\
693 \pm 76 \\
779 \pm 39 \\
-\end{array}$ \\
\hline
\end{tabular}


KINETICS OF DEPOSITION AND CLEARANCE Discussion of these results can be based on a simple kinetic model of deposition and clearance, beginning with that first suggested for asbestos fibres by Morgan et al $^{8}$ and later modified by Middleton et al..$^{5}$ In it the respiratory system of the rat has three notional-that is, mathematical rather than physiological-compartments into which the fibres are deposited in the proportions $87: 5: 8$, and from which they are subsequently cleared exponentially at rates characterised by time constants of the order of $0 \cdot 6,11 \cdot 5$, and 170 days respectively. The first of these (the fast clearance compartment) could be considered to be associated with clearance of fibres deposited in the ciliated and main conducting airways, and the latter two (the medium and the slow clearance compartments) with the clearance of fibres deposited in the respiratory bronchioles or the alveoli. It was suggested, however, that the medium and slow phases of clearance need not necessarily relate to exact anatomical sites of deposition but rather to the degree of "fixation" of deposited dust or to the actual route of clearance.

The results from the build-up experiment shown in fig 2 reflect the competition that exists between deposition and clearance. We can mathematically model the accumulation of dust in the $\mathbf{k}^{\text {th }}$ clearance compartment by assuming a deposition rate of $\alpha_{k}$ units of mass per rat per unit dust exposure level per day's dusting, and a clearance time constant of $\tau_{k}$ days. Assuming that both deposition and clearance are uniform and continuous, the change in the lung burden per unit dust level for the compartment in question during the time interval after start of exposure $\mathrm{T}$ to $\mathrm{T}+\mathrm{dT}$ is

$$
\mathrm{dZ} \mathrm{k}_{\mathrm{k}}=\alpha_{\mathrm{k}} \mathrm{dT}-\frac{\mathrm{Z}_{\mathrm{k}}}{\tau_{\mathrm{k}}} \mathrm{dT} .
$$

Integrating and summing over $\mathrm{n}$ such compartments, the total accumulated lung burden per unit dust level (assuming $\mathrm{Z}=0$ at $\mathrm{T}=0$ ) is

$$
Z=\sum_{k=1}^{n} \alpha_{k} \tau_{k}-\sum_{k=1}^{n} \alpha_{k} \tau_{k} \exp \left(-T / \tau_{k}\right)
$$

Assuming, idealistically, that the biological subject in question is "constant"-that is, the $\alpha$ s and the $\tau \mathrm{S}$ are independent of $\mathrm{T}$-then this model predicts that $\mathrm{Z}$ will increase monotonically with time but will tend eventually to level out. The resultant equilibrium value is

$$
\mathrm{Z} \rightarrow \sum_{\mathrm{k}=1}^{\mathrm{n}} \alpha_{\mathrm{k}} \tau_{\mathrm{k}} \text { as } \mathrm{T} \rightarrow \infty
$$

The build-up picture embodied in this model is con- sistent with that given by Brain and Valberg. ${ }^{15}$ They also considered how such a model should be modified to account for an intermittent exposure pattern-namely, eight hours out of every day for five days out of every week, similar to that for the rats in our experiments. Nevertheless, since the time scales associated with these periodic transients are short by comparison with the time constants associated with clearance in the medium and slow clearance compartments (the main ones of interest) the effects on the overall shape of the build-up curve will be small. Thus, to a fair approximation, we can talk of our experimental data in terms of values for the $\alpha$ s averaged over the whole duration of exposure (including the days when no dusting took place).

In relation to the three compartment deposition and clearance model referred to above the lung burden per unit dust level found in rats exposed for a duration of $\mathrm{T}$ days and then killed at $\mathrm{t}$ days postexposure should be

$$
\begin{aligned}
Z & =\alpha_{\mathrm{f}} \tau_{\mathrm{f}}\left(1-\exp \left(-\mathrm{T} / \tau_{\mathrm{f}}\right)\right) \exp \left(-\mathrm{t} / \tau_{\mathrm{f}}\right) \\
& +\alpha_{\mathrm{m}} \tau_{\mathrm{m}}\left(1-\exp \left(-\mathrm{T} / \tau_{\mathrm{m}}\right)\right) \exp \left(-\mathrm{t} / \tau_{\mathrm{m}}\right) \\
& +\alpha_{\mathrm{s}} \tau_{\mathrm{s}}\left(1-\exp \left(-\mathrm{T} / \tau_{\mathrm{s}}\right)\right) \exp \left(-\mathrm{t} / \tau_{\mathrm{s}}\right)
\end{aligned}
$$

where the suffixes $f, m$, and $s$ refer to the fast, medium, and slow clearance compartments and where $\tau_{\mathrm{f}}=0 \cdot 6, \tau_{\mathrm{m}}=11 \cdot 5$, and $\tau_{\mathrm{s}}=170$ days respectively. ${ }^{7}$

Since the smallest value of $t$ in our experiments was three days, the first term in equation (4) is of no significance (clearance of dust deposited on the airways being virtually complete after three days) and may be ignored in the rest of what follows. From weighted least-squares analysis, the "best fit" of the remaining expression to both sets of the experimental data in fig 2 is achieved when the deposition rates to each compartment are respectively $\alpha_{\mathrm{m}}=2.80$ and $\alpha_{\mathrm{s}}=3.05 \mu \mathrm{g} / \mathrm{mg} \mathrm{m}^{-3} / \mathrm{day}$. So, in general,

$$
\begin{aligned}
Z & =32(1-\exp (-T / 11 \cdot 5)) \exp (-t / 11 \cdot 5) \\
& +518(1-\exp (-T / 170)) \exp (-t / 170)
\end{aligned}
$$

Using this expression, with appropriate values for $T$ and $t$, agreement between the calculated and measured specific lung burdens is seen in fig 2 to be good.

How plausible are these estimates for the $\alpha$-values? A first approximation may be made of the total daily deposition of dust per unit dust exposure level (into all three compartments) as being anything up to (volume of air breathed per rat per day during exposure) $\times 1 \mathrm{mg} \mathrm{m}^{-3}$. For a typical rat in our studies, breathing air at about $100 \mathrm{~cm}^{3} \mathrm{~min}^{-1}$ during normal daylight conditions, the total mass inhaled is about $42 \mu \mathrm{g} / \mathrm{mg} \mathrm{m}^{-3}$ day. Thus the percentages of total deposition into the medium and the slow clearance compartments will be about equal 
and could be as high as $7 \%$ per compartment. This estimate is of the same order of magnitude as the $5 \%$ and $8 \%$ quoted by Morgan et al. ${ }^{8}$

\section{EFFECTS OF PROLONGED EXPOSURE}

What are the consequences of the model in relation to more prolonged exposure? Assuming that the $\alpha \mathrm{s}$ and the $\tau \mathrm{s}$ do not change with time, the first is that the specific lung burden will tend to level out at $\mathrm{Z}=$ $550 \mu \mathrm{g} / \mathrm{mg} \mathrm{m}^{-3}$ as $\mathrm{T} \rightarrow \infty$, reaching $95 \%$ of this final value after about 500 days' exposure. Next there is a limited amount of published data-notably that by Davis $e a^{1}{ }^{1}$ and by Wagner $e t a^{16}$ with which, along with our own data, the model may be compared (see fig 3).

To compare "like with like," these data ${ }^{1-16}$ have been scaled upwards by a factor of 1.20 to compensate for differences in the various dusting programmes that took place in some cases-that is, all the results are normalised to the five days dusting out of every seven, characteristic of own experiments and the model as described by equation (5). In addition, the experimental data of Wagner et al ${ }^{16}$ are further adjusted to account for the differences in breathing volumes between male and female rats (while all the other data shown are for male rats only). From fig 3 we see that, while all the experimental data are essentially in agreement, the predicted lung burdens for prolonged exposure fall a long way short of those actually measured by either group of workers. Such differences cannot be fully explained in terms of changes in rat minute volumes as the animals grow or as pulmonary disease develops, nor in terms of

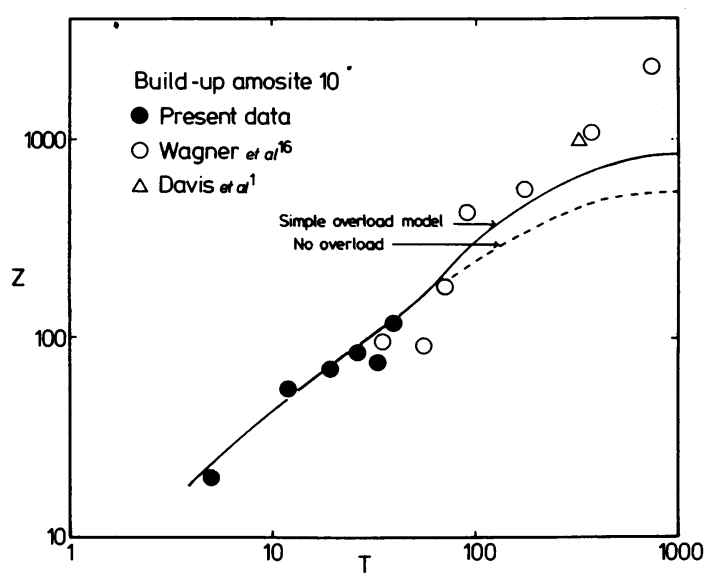

Fig 3 Lung burden per unit level of dust exposure $(Z$, in $\left.\mu \mathrm{g} / \mathrm{mg} \mathrm{m}^{-3}\right)$ as a function of time after start of exposure (T, in days), indicating comparison between present work, previous work, and kinetic model. differences in the recovery and analysis techniques used by the various groups of workers.

The prediction was revised to take simple account of one possible version of clearance "overload"where clearance proceeds normally until the actual lung burden reaches an arbitrarily chosen critical level of $1500 \mu \mathrm{g}$, and thereafter all the dust in the lung together with that subsequently deposited is "transferred" (in the mathematical sense) into the slowest clearing compartment. From fig 3 is seen that this explanation accounts substantially for the original discrepancy.

From our build-up model, the results of our own short term amosite exposure, and the results of the long term amosite exposures of Davis et al $^{1}$ and Wagner $e t$ al ${ }^{16}$ there emerges more evidence to support the idea of clearance overload at high lung burdens. It is strengthened yet further by closer inspection of all the build-up data of Wagner et al; while for amosite the overload threshold seems to be reached early on and so the actual lung burden goes on increasing steadily, for chrysotile that threshold is not reached and so the actual lung burden levels off in much the way predicted by the model for "normal" clearance.

\section{KINETIC INTERPRETATION OF THE CLEARANCE DATA}

The deposition/clearance model, including its modification to include a simple clearance overload process, may now be applied to the clearance data shown in fig 1 . For relatively low level dust exposures, where the clearance overload threshold is not reached during the 40 day inhalation period, $\mathrm{Z}$ as a function of time postexposure $(t)$ is given by equation (5) in which $T=40$ days. For relatively high level dust exposures, equation (5) may be applied until the chosen threshold actual lung burden of $1500 \mu \mathrm{g}$ is reached, whereupon the overload version of the model takes over. On this basis, it is to be expected in this range that $Z$ at $t=0$ will increase appreciably with the level of dust exposure. Figure 4 shows the resultant behaviour which the model predicts for the clearance data already presented in fig 1.

Comparison of figs 1 and 4 shows that the kinetic model exhibits the same trends suggested by the experimental data. That is, the rats with lower initial lung burden cleared faster over the early stages postexposure, and those with higher initial lung burden cleared altogether more slowly. The predicted rates of clearance agree quite well with those measured. More detailed comparison of theory and experiment, however, is less satisfying. For instance, the predicted difference in the clearance curves $(\mathrm{Z}$ versus $t$ ) in fig 4 for the amosite 30 and amosite 90 


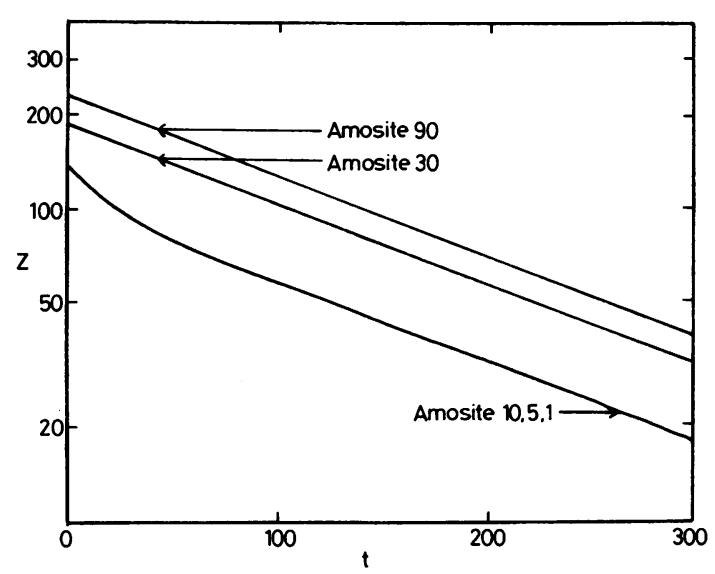

Fig 4 Prediction of clearance curves on basis of kinetic model.

experiments is not apparent in the measured data. Probably, however, at such high concentrations particle agglomeration changes the aerodynamic nature of the airborne dust so as to affect not only the measurement of the airborne dust concentration but also the regional deposition in the lungs of the rats. Electrostatic effects might also contribute. ${ }^{17}$

The clearance curves for the reverse daylight experiments seem to behave as if the overload threshold has been reached and passed during the exposure period, even though the magnitudes of the mean lung burdens (table 1) are more consistent with those associated with normal clearance. This too could be due to the differences in the regional deposition of the inhaled dust, this time between normal daylight (rats inactive) and reverse daylight (rats active) conditions. Nevertheless, in the absence of more detailed information about breathing patterns and regional deposition in rats for the conditions of interest it is not possible to offer a more comprehensive explanation.

\section{BIOLOGICAL INTERPRETATIONS OF THE KINETIC} MODEL

It is important to note that in the present study the overload condition was identified in the absence of any observed major structural changes to the lung. The only widespread and consistent histopathological evidence of dust exposure was the presence of dust laden macrophages in parenchymal lung of all animals. No specific attempt is made to relate the extent of such accumulations to specific dust treatment in the present paper, although such assessments will be undertaken and reported separately. While there is a suggestion from relating the kinetic model to the measured lung burdens that clearance is mediated by retardation of the medium clearance phase, it is not possible from present information to determine whether this results from a failure of macrophage recruitment, a restriction of dust laden macrophage mobility, or simply that a greater proportion of deposited dust obtains direct entry to the notional fixed tissue compartment.

A detailed discussion of the significance of these interrelated, but functionally distinct, aspects is beyond the scope of the present paper and will be examined elsewhere (RE Bolton, D Hannant, unpublished observations). Nevertheless the role of the macrophage in pulmonary clearance has been examined by many workers. ${ }^{18-20}$ It is known, for example, that alveolar macrophages are produced in increased numbers after dust challenge ${ }^{21-24}$ that the increase seems to be related to the number of dust particles available for phagocytosis, ${ }^{2526}$ and that both monocyte recruitment and maturation and cell division, ${ }^{27-29}$ both interstitially ${ }^{29}$ and in the alveolar free space, ${ }^{30-32}$ can contribute to the overall increase in cell numbers. The role of the macrophage in cell recruitment at inflammatory sites has been widely studied, ${ }^{33}$ although the specific capabilities of the alveolar macrophage have been examined only comparatively recently.3435 The process of phagocytosis has been shown to be associated with macrophage activation. ${ }^{3637}$ More specifically, phagocytosis of asbestos has been shown to produce activation of macrophage in vitro ${ }^{3839}$ and in vivo. ${ }^{40-42}$ Macrophage activation is known to induce varying degrees of involvement of inflammatory and immune response, including the production and release of chemotactic factors. ${ }^{434}$ Since the degree of alveloar macrophage recruitment in the lung is related to the number of dust particles (and therefore the number of phagocytic events), and phagocytosis results in activated macrophages which may be capable of producing chemotactic and other factors, a role for cell recruitment in normal pulmonary clearance can be envisaged.

The existence of a condition of clearance overload implies a failure of this normal cellular process and, as we have already stated, several authors have produced evidence of an overload similar to our own ${ }^{12-14}$ (TJ Vostal, Raleigh, October 1981). Adamson and Bowden showed that high doses of dust can overload macrophage cell division within the lung. ${ }^{26}$ Several workers have reported macrophage accumulations around the respiratory bronchioles in a dose dependent manner ${ }^{45-47}$ (TL Chan et al, at Society of Toxicology Conference at Boston, USA, 23-26 February 1982), and there is evidence that aggregations of macrophages may have an inhibitory effect on each other under certain circumstances. ${ }^{48} 49$ Thus published reports provide consid- 
erable evidence for a relative failure both in cell recruitment and in the mobility of recruited cells. Further work is necessary to examine the details and consequences of these factors.

\section{Perspective}

The weight of the evidence for an overload hypothesis in relation to pulmonary clearance mechanisms under certain experimental conditions is persuasive. The phenomenon in question would not appear to be specific for any one type of dust since coal, quartz, diesel fumes, and asbestos have all been shown to exhibit overload at similar levels of lung burden. Whether the overload is due to the exceeding of a critical lung burden, to a high concentration of airborne dust (and hence a high deposition rate), or to physiologically mediated changes in the zonal deposition patterns is arguable. Our evidence, however, provides support for the theory that lung burden itself can have a profound effect on particle clearance. Human evidence of clearance overload is difficult to obtain due to the problems associated with making realistic estimates of past exposure and to the likely interfering effects of such factors as smoking and pre-existing pulmonary disease. It is interesting to note, however, that pulmonary dust burdens in excess of those found in our rat experiments (in $\mu \mathrm{g}$ dust/gram dry weight of lung) are regularly found at necropsy in men from industrial environments. ${ }^{5051}$ It is therefore entirely possible that a similar phenomenon pertains to people.

The apparent independence of this overload condition on the nature of the inhaled dusts is particularly interesting since it implies that in exposures to complex dust mixtures, the level of total respirable dust must be taken into account in assessing the potential effects of exposure, it being the total burden of dust in the lung that will influence the residence time (and hence potential pathogenicity) of any of the individual constituents. This could have important implications for the control in the workplace of nuisance dusts containing relatively small proportions of toxic material.

A further implication of the existence of an overload condition concerns the design of inhalation toxicological studies. The present work has shown that during exposure to asbestos at high concentrations (up to three orders of magnitude greater than the TLV for amosite), the burden of dust in the rat lungs soon reaches levels at which an overload of the clearance mechanisms obtains. This highlights the need for dose response inhalation toxicological studies in which the highest doses provide information on the worst case consequences of excess exposure, and lower doses provide information on the relevance of any demonstrated toxicity under more realistic conditions. The present work shows that chronic exposure of rats to respirable asbestos dust concentrations exceeding $5 \mathrm{mg} \mathrm{m}^{-3}$ for periods in excess of six weeks may indeed involve impaired pulmonary clearance and therefore increased persistence of deposited dust. It does not imply, however, that any resulting pathogenicity is necessarily inappropriate. Davis ${ }^{52}$ has shown that under just these conditions the rat develops asbestos related pulmonary diseases qualitatively similar in pathology to those encountered in heavy exposure industries and described in many epidemiological studies. ${ }^{53}$

The work was carried out with the financial support of the Asbestosis Research Council. We thank the numerous colleagues at the Institute of Occupational Medicine who also contributed, through their technical support, to this inquiry.

\section{References}

' Davis JMG, Beckett ST, Bolton RE, Collings P, Middleton AP. Mass and number of fibres in the pathogenesis of asbestosrelated lung disease in rats. $B J$ Cancer 1978;37:673-88.

${ }^{2}$ Davis JMG, Beckett ST, Bolton RE, Donaldson K. The effects of intermittent high asbestos exposure (peak dose levels) on the lungs of rats. $B J$ Exp Patho 1980;61:272-80.

${ }^{3}$ Davis JMG, Beckett ST, Bolton RE, Donaldson K. A comparison of the pathological effects in rats of the UICC reference samples of amosite and chrysotile with those of amosite and chrysotile collected from the factory environment. In: Wagner JC, ed. Biological effects of mineral fibres. Lyon: International Agency for Research on Cancer, 1980:285-92. (IARC scientific publication No 30.)

4 Middleton AP, Beckett ST, Davis JMG. A study of the shortterm retention and clearance of inhaled asbestos by rats, using UICC standard reference samples. In: Walton WH, ed. Inhaled particles IV. Oxford: Pergamon Press, 1977:247-57.

5 Middleton AP, Beckett ST, Davis JMG. Further observations on the short-term retention and clearance of asbestos by rats, using UICC reference samples. Ann Occup Hyg 1979;22:141-52.

6 Wagner JC, Skidmore JW. Asbestos dust deposition and retention in rats. Ann NY Acad Sci 1965;132:77-86.

${ }^{7}$ Morgan A, Evans JC, Evans RJ, Hounam RF, Holmes A, Doyle SG. Studies on the deposition of inhaled fibrous material in the respiratory tract of the rat and its subsequent clearance using radioactive tracer techniques. II. Deposition of the UICC standard reference samples of asbestos. Environ Res 1975;10:196-207.

Morgan A, Evans JC, Holmes A. Deposition and clearance of inhaled fibrous minerals in the rat. Studies using radioactive tracer techniques. In: Walton WH, ed. Inhaled particles IV. Oxford: Pergamon Press, 1977:259-72.

' Beckett ST. The generation and evaluation of UICC asbestos clouds in animal exposure chambers. Ann Occup Hyg 1975;18:187-98.

${ }^{10}$ Dunmore JH, Hamilton RJ, Smith DSG. An instrument for the sampling of respirable dust for subsequent gravimetric assessment. Journal of Scientific Instruments 1964;41:660-72.

$"$ Gleit CE, Holland WD. Use of electrically-excited oxygen for the low temperature decomposition of organic substances. Anal Chem 1962;34:1454-7. 
${ }^{12}$ Klosterkotter W, Bunemann G. Animal experiments on the elimination of inhaled dust. In: Davies $\mathrm{CN}$, ed. Inhaled particles and vapours. Oxford: Pergamon Press, 1961:327-37.

${ }^{13}$ Ferin F. Observations concerning alveolar dust clearance. Ann NY Acad Sci 1972;200:66-72.

${ }^{14} \mathrm{Le}$ Bouffant $\mathrm{L}$. Influence de la nature des poussieres et de la charge pulmonair sur l'epuration. In: Walton WH, ed. Inhaled partices III. Oxford: Pergamon Press, 1971:227-37.

is Brain JD, Valberg PA. Models of lung retention based on ICRP task group report. Arch Environ Health 1974;28:1-11.

${ }^{16}$ Wagner JC, Berry G, Skidmore JW, Timbrell V. The effects on the inhalation of asbestos in rats. Br J Cancer 1974;29:25269.

17 Vincent JH, Johnston WB, Jones AD, Johnston AM. Static electrification of airborne asbestos: a study of its causes, assessment and effects on deposition in the lungs of rats. Am Ind Hyg Ass J 1981;42:711-21.

18 Green GM, Jakab GJ, Low RB, Davis GS. Defence mechanisms of the respiratory membrane. Am Rev Respir Dis 1977;115:479-514.

19 Brain JD. Macrophage damage in relation to the pathogenesis of lung diseases. Environ Health Perspect 1980;35:21-8.

${ }^{20}$ Lippmann M, Yeates DB, Albert RE. Deposition, retention, and clearance of inhaled particles. Br J Ind Med 1980;37:337-62.

${ }^{21}$ Brain JD. Free cells in the lungs. Some aspects of their role, quantitation, and regulation. Arch Intern Med 1970;126:477-87.

22 Tetley TD, Hext PM, Richards RJ, McDermott M. Chrysotileinduced asbestosis: changes in the free cell population, pulmonary surfactant and whole lung tissue of rats. Br J Exp Pathol 1976;57:505-14.

${ }^{23}$ Morgan A, Moores SR, Holmes A, Evans JC, Evans NH, Black $A$. The effect of quartz, administered by intratracheal instillation, in the rat lung. Environ Res 1980;22:1-12.

${ }^{24}$ Hatch GE, Gardner DE, Menzel DB. Stimulation of oxidant production in alveolar macrophages by pollutant and latex particles. Environ Res 1980;23:121-6.

${ }^{25}$ Labelle $\mathrm{CW}$, Brieger $\mathbf{H}$. The fate of inhaled particles in the early postexposure period. II The role of pulmonary phagocytosis. Arch Environ Health 1960;1:423-7.

${ }^{26}$ Adamson IYR, Bowden DH. Dose response of the pulmonary macrophagic system to various particulates and its relationship to transepithelial passage of free particles. Exp Lung Res 1981;2:165-75.

${ }^{27}$ Bluss A, Alblas O, Linden-Schrever B, Van Furth R. Origin and kinetics of pulmonary macrophages during an inflammatory reaction induced by intravenous administration of heat-killed Bacillus Calmette-Guerin. J Exp Med 1981;154:235-52.

${ }^{28}$ Hockings WG, Golde DW. The pulmonary alveolar macrophage. N Engl J Med 1979;301:580-7.

${ }^{29}$ Adamson IYR, Bowden DH. Role of monocytes and interstitial cells in the generation of alveolar macrophages. Lab Invest 1980;42:518-24.

${ }^{30}$ Boorman GA, Schwartz LW, Wilson FD. Formation of macrophage colonies in vitro by free lung cells obtained from rats. $J$ Reticuloendothel Soc 1979;26:855-66.

${ }^{31}$ Evans MJ, Cabral LJ, Stephens RJ, Freeman G. Cell division of alveolar macrophages in rat lung following exposure to $\mathrm{NO}_{2}$. Am J Pathol 1973;70:199-208.

${ }^{32}$ Luchtel DL, Naum Y. Ultrastructural characteristics of pulmonary alveloar macrophages induced to multiply in vitro. In: Sanders CL, Schneider RP, Dagle GE, Ragan HA, ed. Pulmonary macrophage and epithelial cells. Springfield: Energy Research and Development Administration, 1977:298-317.

${ }^{33}$ Edelson PJ. Monocytes and macrophages: aspects of their cell biology. In: Glynn LE, Houck JC, Weissman G, eds. Handbook of inflammation II. The cell biology of inflammation. Amsterdam: Elsevier, North Holland, 1980:470-95.

${ }^{34}$ Kazmierowski JA, Aduan RP, Reynolds HY. Pulmonary host defense: co-ordinated interaction of mechanical, cellular and humoral immune systems of the lung. Bull Eur Physiopathol Respir 1977;13:103-16.

${ }^{35}$ Kaltreider HB. Expressions of immune mechanisms in the lung. Am Rev Respir Dis 1976;113:347-79.

${ }^{36}$ Schnyder J, Baggiolini M. Role of phagocytosis in the activation of macrophages. J Exp Med 1978;148:1449-57.

${ }^{37}$ Oropeza-Rendon RL, Ernst M, Schade U, Rietschel ET, Fischer H. Activation of bone marrow derived macrophages by repeated zymosan phagocytosis leads to enhanced prostoglandic sythesis. Immunobiology 1981;160:208-16.

${ }^{38}$ Davies P, Allison AC, Ackerman J, Butterfield A, Williams S. Asbestos induces selective release of lysosomal enzymes from mononuclear phagocytes. Nature 1974;251:423-5.

${ }^{39}$ Hamilton J, Vassalli JD, Reich E. Macrophage plasminoge activator: induction by asbestos is blocked by antiinflammatory steroids. J Exp Med 1976;144:1689-94.

${ }^{40}$ Miller K, Kagan E. The in vitro effects of asbestos on macrophage membrane structure and population characteristics of macrophages: a scanning electron microscope study. $J$ Reticuloendothel Soc 1976;20:159-71.

${ }^{41}$ Hamilton JA. Macrophage stimulation and the inflammatory response to asbestos. Environ Health Perspect 1980;34:69-74.

${ }^{42}$ Donaldson K, Davis JMG, James K. Characteristics of peritoneal macrophage induced by asbestos injection. Environ Res 1982;29:414-24.

${ }^{43}$ Hunninghake GW, Gallin JI, Fauci AS. Immunologic reactivity of the lung. The in vivo and in vitro generation of a neutrophil chemotactic factor by alveolar macrophages. Am Rev Respir Dis 1978;117:15-23.

${ }^{44}$ Cohn ZA. The activation of mononuclear phagocytes: fact, fancy and future. J Immunol 1978;121:813-5.

${ }^{45}$ Labelle CW, Briegar H. Synergistic effects of aerosols. II Effects on rate of clearance from the lung. Archives of Industrial Health 1959;20:100-5.

${ }^{46}$ Pepelko WE, Mattox JK, Yang YY, Moore W. Pulmonary function and pathology in cats exposed to diesel exhaust. J Environ Pathol Toxicol 1980;4:449-58.

${ }^{47}$ Strom KA. Response of pulmonary cellular defenses to the inhalation of high concentrations of diesel exhaust. In: Lewtas S, ed. Toxicological effects of emissions from diesel engines. New York: North Holland, Elsevier (in press).

48 Yeh SE, Stewart CC. Macrophage growth inhibitors derived from the murine peritoneal cavity. In vitro $1981 ; 17: 871-6$.

${ }^{49}$ Strom KA, Garg BD. Post exposure diesel particle residence in the lungs of rats following inhalation of dilute diesel exhaust for six months. In: Lewtas S, ed. Toxicological effects of emissions from diesel engines. New York: North Holland, Elsevier (in press).

${ }^{\text {so }}$ Nagelschmidt G. Some observations of the dust content and composition in lungs with asbestosis made during work on coal miners pneumoconiosis. Ann NY Acad Sci 1965;132:64-76.

s1 Ruckley VA, Chapman JS, Collings PL, et al. Autopsy study of coalminers' lungs - phase II. (Final report on CEC Contract 7246-15/8/001.) Edinburgh: Institute of Occupational Medicine, 1981. (IOM Report TM/81/18.)

${ }^{32}$ Davis JMG. The use of animal inhalation experiments in the study of asbestos bioeffects. Staub-Reinhaltung der Luft 1980;40:453-5.

${ }^{53}$ Health and Safety Commission. Asbestos. Vol 1. Final report on the advisory committee. London: HMSO, 1979. 